\title{
Association of ABO blood groups and Von Willebrand Factoramong Sudanese individual in Khartoum Sudan
}

\author{
Mohamed Abdallabakheit eltaher ${ }^{1}$, Mahdi H. A. Abdalla ${ }^{2}$ \\ ${ }^{1}$ Department of Haematology, Faculty of Medical Laboratory Sciences, \\ Al-Neelain University, Khartoum, Sudan. \\ ${ }^{2}$ Associated Professor of Haematology, Department of Haematology, \\ Faculty of Medical Laboratory Sciences, Omdurman Ahlia University, Khartoum, Sudan.
}

\begin{abstract}
:
Background: Von Willebrand factor (VWF) is a large adhesive glycoprotein synthesized by endothelial cells and megakaryocytes. The antigens of the $\mathrm{ABO}$ system (A, B, and $\mathrm{H}$ determinants, respectively) consist of complex carbohydrate molecules. ABO blood group locus on chromosome 9q34exert major quantitative effects on VWF level.
\end{abstract}

Objective: The purpose of this study was toevaluate the association of Different ABO blood groups and VWF level among Sudanese Subjects.

Materials and Methods:Eighty-two samples were included in this study, Von Willebrand factor levels were determined among various blood groups. VWF was determined using ELISA method and Blood group was determined by using direct blood group method.

Results: The males were $56(68 \%)$ and Females were $26(32 \%)$. The frequencies of different blood groups were as follows: AB 10 (12.2\%), A 21 (25.6\%), B 12 (14.6\%) and O 39 (47.6). VWF levelswere significantly higher in non-group $\mathrm{O}$ than group $\mathrm{O}$ individuals.

Conclusion: This study has concluded that VWF: Ag level is higher in non-group O than in group O individuals.

Keywords:, ABO, Blood group, Von Willebrand Factor, Sudanese.

\section{Introduction}

Von Willebrand factor (VWF) is a large adhesive glycoprotein synthesized by endothelial cells and megakaryocytes that circulates in the plasma as a series of heterogeneous multimers. ${ }^{[1][2]}$

VWF has two major functions in hemostasis. First, it is essential for platelet-subendothelium adhesion and platelet-to-platelet interactions as well as platelet aggregation in vessels in which rapid blood flow results in elevated shear stress. Second, VWF is the specific carrier of factor VIII (FVIII) in plasma and protects it from proteolytic degradation, prolonging its half-life in circulation and efficiently localizing it at the site of vascular injury. ${ }^{[3]}$

While a deficiency of VWF is responsible for a hemorrhagic disorders (von Willebrand disease, VWD) ${ }^{[4]}$ there are increasing evidences that elevated VWF levels represent an important thrombotic risk factor. ${ }^{[5][6]}$

Besides the VWF gene (12p12), it is well established that other gene loci exert major quantitative effects on VWF plasma levels.

The most important of these loci has been shown to be the ABO blood group locus on chromosome $9 \mathrm{q} 34 .{ }^{[7][8]}$ 
The antigens of the $\mathrm{ABO}$ system (A, B, and $\mathrm{H}$ determinants, respectively) consist of complex carbohydrate molecules. The A and B alleles encode slightly different glycosyltransferases that add $\mathrm{N}$-acetylgalactosamine and $\mathrm{D}$-galactose, respectively, to a common precursor side chain, the $\mathrm{H}$ determinant, converting it into $\mathrm{A}$ - or $\mathrm{B}$-antigens. The $\mathrm{O}$ alleles do not encode a functional enzyme and consequently OO carriers, who lack such transferase enzymes, continue to express the basic, unmodified, $\mathrm{H}$-antigen with a fucose moiety attached to precursor oligosaccharide chains. ${ }^{[9]}$ The purpose of this study was toevaluate the association of Different ABO blood groups and VWF level among Sudanese Subjects.

\section{Materials and Methods}

This study is a cross-sectional study, conducted in Khartoum, Sudan. Eighty two samples from healthy participants were included in this study. All of them were evaluated to determine the association of ABO blood group and VWF level among Sudanese population.

$3 \mathrm{ml}$ of venous blood was collected from each subject. $2 \mathrm{ml}$ in $3.8 \%$ trisodium citrate $(9: 1$ $\mathrm{vol} / \mathrm{vol}$ ), kept on ice until centrifugation at $2500 \mathrm{gfor} 30$ minutes at $4^{\circ} \mathrm{C}$, plasma samples were immediatelyfrozen and stored at $-80^{\circ} \mathrm{C}$ for subsequent analysis;and $1 \mathrm{ml}$ in EDTA for the $\mathrm{ABO}$ blood grouping. Laboratory analysis was performed at the Department of Haematology, Faculty of Medical Laboratory Sciences, Alneelain University.

Estimation of VWF was carried out using Enzyme Linked Immunosorbent Assay (ELISA) method with kit obtained from technoclone, Vienna, Austria (Lot 3015983). Test was run using EUROIMMUN Analyzer I-2P $®$. ABO phenotypes were determined by direct method. This study was approved by ethical committee of ministry of health, and informed consent was obtained from each participant before sample collection.

Statistical analyses were performed using SPSS software, one way analysis of variance (ANOVA) was used to compare the mean \pm SD of VWF levels between the various ABO blood group phenotypes.

\section{Results}

The study included 56 males $(68 \%)$ and 26 females (32\%). There was no significant difference in the mean of the VWF between males $(0.66 \pm 0.26)$ and females $(0.68 \pm 0.22)$. Table 1 showed the mean levels of VWF among different ABO phenotypes. Mean VWF level was significantly higher among non-O blood groups than O blood group (TABLE 2).

Table 1.Distribution of Individuals VWF levels among the several blood group

\begin{tabular}{|c|c|c|c|}
\hline Blood group & Frequency (N) & Percentage (\%) & $\begin{array}{c}\text { Mean } \pm \text { SD } \\
\text { (VWF) }\end{array}$ \\
\hline AB & 10 & 12 & $0.97 \pm 0.16$ \\
\hline A & 21 & 26 & $0.76 \pm 0.28$ \\
\hline B & 12 & 15 & $0.69 \pm 0.16$ \\
\hline O & 39 & 48 & $0.55 \pm 0.19$ \\
\hline Total & 82 & 100 & $0.68 \pm 0.25$ \\
\hline
\end{tabular}


Table 2. VWF levels between the severalblood groups

\begin{tabular}{|c|c|c|c|c|c|}
\hline (I) Blood group & (J) Blood group & Difference (I-J) & Std. Error & $\boldsymbol{P}$-value & Remark \\
\hline \multirow{2}{*}{ AB } & $\mathrm{A}$ & 0.208 & 0.080 & .044 & $\mathrm{~S}$ \\
\cline { 2 - 6 } & $\mathrm{B}$ & 0.278 & 0.089 & .013 & $\mathrm{~S}$ \\
\cline { 2 - 6 } & $\mathrm{O}$ & 0.419 & 0.074 & .000 & $\mathrm{~S}$ \\
\hline \multirow{3}{*}{$\mathbf{A}$} & $\mathrm{AB}$ & -0.208 & 0.080 & .044 & $\mathrm{~S}$ \\
\cline { 2 - 6 } & $\mathrm{B}$ & 0.070 & 0.076 & .789 & $\mathrm{~N} / \mathrm{S}$ \\
\cline { 2 - 6 } & $\mathrm{O}$ & 0.211 & 0.056 & .002 & $\mathrm{~S}$ \\
\hline \multirow{2}{*}{ B } & $\mathrm{AB}$ & -0.278 & 0.089 & .013 & $\mathrm{~S}$ \\
\cline { 2 - 6 } & $\mathrm{A}$ & -0.070 & 0.076 & .789 & $\mathrm{~N} / \mathrm{S}$ \\
\cline { 2 - 6 } & $\mathrm{O}$ & 0.140 & 0.069 & .183 & $\mathrm{~N} / \mathrm{S}$ \\
\hline \multirow{2}{*}{$\mathbf{O}$} & $\mathrm{AB}$ & -0.419 & 0.074 & .000 & $\mathrm{~S}$ \\
\cline { 2 - 6 } & $\mathrm{A}$ & -0.211 & 0.056 & .002 & $\mathrm{~S}$ \\
\cline { 2 - 6 } & $\mathrm{B}$ & -0.140 & 0.069 & .183 & $\mathrm{~N} / \mathrm{S}$ \\
\hline
\end{tabular}

The mean difference is significant at the 0.05 level. (S) Significant (N/S) Non- significant

\section{Discussion}

Von Willebrand factor is one of the few non-erythrocytic proteins that express ABO antigens.ABH oligosaccharide structure has been identified on the $\mathrm{N}$-linked oligosaccharide chains of VWF located on the A1 domain which contains the binding site for platelet glycoprotein. we evaluated the association of Different ABO blood groups and VWF level among Sudanese Subjects.

Our study has shown that VWF levels are significantly higher among non-O blood groups than O blood group individuals. Similar findings have been reported in other studies. Asuquo James I et al, [10] inNigeria reported that blood group $\mathrm{O}$ showed lower VWF levels than non-group $\mathrm{O}$ individuals. in a large study of 1117 healthy individuals conducted by Gill and colleagues [11], plasma VWF levels were lowest in group $\mathrm{O}$ (mean von Willebrand factor antigen and highest in group $\mathrm{AB}$ subjects.

Two possibilities may exist one is the increase synthesis of VWF in non- $\mathrm{O}$ individual, the other is that increase clearance of VWF in group $\mathrm{O}$ individuals, but this mechanism is still controversial. O'Donnell et al, ${ }^{[8]}$ postulated that the increased clearance is facilitated by hepatic receptor that has affinity for $\mathrm{H}$ antigen, but findings that individuals with Bombay phenotype that also lack $\mathrm{H}$ antigen have lower levels of the factor than blood group OO genotype does not support such claim [10].It is most likely that the nature of carbohydrate in $\mathrm{ABO}$ antigen determines the rate of proteolysis.

\section{Conclusion}

In conclusion, this study has concluded that VWF levels were higher among non-group $\mathrm{O}$ than group $\mathrm{O}$ individuals.

\section{Acknowledgement}

Special thanks to the Staff of Haematology Department, Faculty of Medical Laboratory Sciences, Alneelain University, Sudan.

\section{References}

[1]. Ruggeri ZM, Zimmerman TS. The complex multimeric composition of factor VIII/vWF. Blood.1981;57:1140-1143.

[2]. Sadler JE. vonWillebrand factor. Ann Rev Biochem. 1998;67:395-424. doi: 10.1146/annurev.biochem.67.1.395.

[3]. Ruggeri ZM. Structure of von Willebrand factor and its function in platelet adhesion and thrombus formation. Best PractResClinicalHaematol. 2001;14:257-259. doi: 10.1053/beha.2001.0133. 
[4]. Vlot AJ, Koppelman SJ, Bouma BN, Sixma JJ. Factor VIII and von Willebrand Factor. ThrombHaemost. 1998;79:456-465.

[5]. Ruggeri ZM, Zimmerman TS. vonWillebrand factor and von Willebrand disease. Blood. 1987;70:895904.

[6]. Whincup PH, Danesh J, Walker M, Lennon L, Thomson A, Appleby P, Rumley A, Lowe GD. von Willebrand factor and coronary heart disease: prospective study and meta-analysis. Eur Heart J.2002;23:1764-1770.

[7]. Franchini M, Lippi G. Von Willebrand factor and thrombosis. Ann Hematol. 2006;85:415-423. doi: 10.1007/s00277-006-0085-5.

[8]. O'Donnell JS, Lasffan MA. The relationship between ABO histo-blood group, factor VIII and von Willebrand factor. Transfus Med. 2001;11:343-351.

[9]. Jenkins PV, O'Donnell JS. ABO blood group determines plasma von Willebrand factor levels: a biologic function after all? Transfusion. 2006;46:1836-1844.

[10]. Asuquo James I et al,International Journal of Biomedical Laboratory Science (IJBLS) 2014 Vo1. 3 , No. 1:24-28.

[11]. Gill JC, Endres-Brooks J, Bauer PJ, Marks WJ Jr, Montgomery RR: The effect of ABO blood group on the diagnosis of von Willebrand disease. Blood 1987, 69:1691-1695. 